\title{
TITLE:
}

\section{On the removal of critical cutting regions by trochoidal grooving}

AUTHOR(S):

Ibaraki, Soichi; Yamaji, Iwao; Matsubara, Atsushi

CITATION:

Ibaraki, Soichi ...[et al]. On the removal of critical cutting regions by trochoidal grooving. Precision Engineering 2010, 34(3): 467-473

ISSUE DATE:

2010-07

URL:

http://hdl.handle.net/2433/113248

RIGHT:

(c) 2010 Elsevier B.V.; この論文は出版社版でありません。引用の際には 出版社版をご確認ご利用ください。; This is not the published version. Please cite only the published version. 


\title{
On the Removal of Critical Cutting Regions by Trochoidal Grooving
}

\author{
Soichi Ibaraki*,Iwao Yamaji, and Atsushi Matsubara \\ Department of Micro Engineering, Kyoto University \\ Yoshida-honmachi, Sakyo-ku, Kyoto, 606-8501, Japan
}

\begin{abstract}
Particularly in high-speed roughing by a straight end mill, contour-parallel paths often cause an excessive tool load in a critical cutting region such as a sharp corner and a narrow slot. Trochoidal grooving can be used to remove such regions safely, prior to high-speed contour-parallel cutting. This paper present a systematic tool path generation strategy for high-speed 2-1/2 dimensional end milling with the removal of critical cutting regions by trochoidal grooving. We first present a scheme to extract critical cutting regions for an arbitrary two-dimensional pocket contour by using its medial axis. A trochoidal tool path to remove an arbitrary contour can be generated also by using the medial axis. Two experimental case studies are presented to show the efficiency and tool wear progress in the roughing by a straight end mill with trochoidal grooving to remove critical cutting regions, in comparison with conventional contourparallel roughing by a ball end mill.
\end{abstract}

Key Words: trochoidal grooving, contour-parallel tool path, roughning, straight end mill, Voronoi diagram, medial axis.

${ }^{*}$ Corresponding author: Address: Department of Micro Engineering, Kyoto University, Yoshidahonmachi, Sakyo-ku, Kyoto, 606-8501, Japan; phone: +81-75-753-5227; fax: +81-75-753-5227; email:ibaraki@prec.kyoto-u.ac.jp 


\section{Introduction}

In die and mold machining, roughing by a straight end mill potentially enhances the productivity significantly, compare to typical cases where a ball end mill is used throughout the entire process. A straight end mill allows a larger axial depth of cut, which significantly reduces the number of layers in the z-direction in $2-1 / 2$ dimensional machining. In early '90s, a sintered carbide end mill with an (Al, Ti) N coating was introduced to the market, which made it possible to directly machine pre-heated hardened steel. By first performing heat treatment on raw steel and then machining it by using such a tool, die/mold making process can be significantly simplified, potentially eliminating a need for grinding or electric discharging machining processes. Particularly for such a hardened steel, the machining by a straight end mill often requires an experienced operator to perform very careful process planning to avoid severe cutting problems. Commercial CAM software mostly adopt either direction-parallel or contour-parallel paths, which are both generated by successive offsets of the input boundary to be machined. Since they are computed solely from the geometry of the input boundary with almost no concern about machining process, contour-parallel paths often create some cutting problems. To be noted among them is significantly varying cutting engagement that causes the variations in cutter load [1]. Since a straight end mill with a larger axial depth of cut is often subject to larger cutting load, such a variation may damage a tool easily.

Many researches in the literature parameterized the variation in cutting load by the engagement angle of a tool to the workpiece $[2,3]$. Shown in Fig. 1 is how cutting engagement angle varies depending on the geometry of the tool path in the two-dimensional (2D) ma- 
chining. The engagement angle represents the geometric interference between the tool and the workpiece in the two-dimensional machining. It is thus clear that the engagement angle is one of dominant process parameters that determines the cutting load on the tool, although its influence significantly depends on many other process parameters such as the helix angle of tool, the number of flutes, and the axial depth of cut. Figure 1 also illustrates an abrupt increase of the engagement angle at a sharp corner.

To avoid the variation in cutting force on arbitrary tool paths, major methods reported in the literature are adjusting the feedrate adaptively. Model-based feedrate scheduling schemes, where a process simulator predicts the cutting force along the given tool path and optimizes the feedrate in priori, have been extensively studied since the 1960s [4, 5, 6]. Some latest commercial CAM software use the MRR (material removal rate)-based simulator to optimize NC program feedrate. Although feedrate scheduling may be effective to regulate cutting force on smooth tool paths, it is often ineffective to avoid cutting problems at corners. Since cutting force increases almost instantaneously at a sharp corner, it is in practice difficult to completely avoid it by feedrate scheduling [7]. Since tool paths for mold machining often contain many corners, too frequent slow down for cutting force regulation may significantly sacrifices the overall productivity. Furthermore, a study [8] showed that longer engagement to the workpiece at a corner could increase the tool temperature, which potentially shortens the tool life even when cutting force is regulated by feedrate scheduling.

To avoid larger cutting engagement at a corner, a tool path itself must be modified. Some researchers proposed an attempt to minimize the cutting load at a corner by inserting additional looping tool paths $[9,10,11]$. This strategy is adopted in some latest commercial CAM software. 
The trochoidal grooving can be seen as an extension of this strategy to remove a larger class of critical cutting regions, including a slot requiring full-immersion cutting. As is illustrated in Fig. 2, trochoidal grooving cuts a slot by successive circular paths to avoid a full-immersion configuration. The idea of employing trochoidal grooving is recent [12], but their great potential is already recognized by many CAM vendors (e.g. MasterCAM by CNC Software, Inc., CAM TOOL by Graphic Products, Inc., and CATIA V5 by Dassualt Systemes). A commercial add-on software to implement trochoidal grooving is also available (Volumill by Celeritive Technologies, Inc.).

To our knowledge, these commercial software can only insert trochoidal grooving to all slots or a looping arc to all corners. Otherwise they require a human operator to manually locate trochoidal grooving. In this paper, we will show that critical cutting regions are not only at a sharp corner or a narrow slot, but inevitably appear in many parts on contourparallel paths. The objective of this paper is to present a systematic tool path generation strategy for high-speed 2-1/2 dimensional end milling based on the recognition of critical cutting regions, and their removal by trochoidal grooving. We will first present a scheme to generate a trochoidal tool path to remove an arbitrary contour by using the medial axis, a sub-set of the Voronoi diagram computed from the given contour to be machined. The extraction of critical cutting regions can be performed also based on the medial axis of the contour. Law et al. [13] presented a machining scheme to remove diagonals of a rectangular pocket prior to contour-parallel machining. The present scheme to remove critical cutting regions can be seen as its extension to general cases. Practical case studies of $2-1 / 2$ dimensional machining of a cavity mold is presented to demonstrate the application of trochoidal grooving to high-speed roughing by a straight end mill. 
Lately, some studies $[12,14]$ reported the geometric analysis of trochoidal tool paths for the optimization of machining conditions. To our knowledge, few studies have been reported on its application strategy to remove critical cutting regions. Its experimental demonstration will be also of a practical importance to understand its effectiveness in practical industrial machining applications.

\section{Trochoidal tool path generation by using medial axis}

This section first presents an algorithm to generate a trochoidal tool path to remove the region within the given arbitrary 2D contour. From the theory of Voronoi diagrams, it can be shown that the center of a circle inscribing the contour is located on the medial axis, a subset of the Voronoi diagram, of the given contour. The authors [15] presented an algorithm to generate a trochoidal tool path by using the medial axis. Elber et al. [16] later presented an analogous algorithm. This section only briefly reviews this algorithm.

The Voronoi diagram and the medial axis are defined as follows (see e.g. [17] for its more mathematically strict definition): consider a set, $S$, of disjoint points and straight-line segments in the 2D Euclidean space. The points and line segments contained in $S$ are called sites. The Voronoi diagram of $S, V D(S)$, is defined as a set of points which have at least two sites in $S$ in the same distance, and all the other sites in $S$ are further than them. A set of segments contained in $V D(S)$ excluding those connected to a reflex vertex of $S$ is called the medial axis of $S, M A(S)$. Figure 3 shows their illustrative examples [17].

For the computation of parallel offsets, there have been numerous research efforts to build algorithms with higher robustness and smaller computational complexity [18], including the 
ones based on the Voronoi diagram [19]. Algorithms to generate Voronoi diagrams have been also extensively studied. In this paper, we adopt the VRONI package developed by Held [20] implemented in ANSI C codes.

Suppose that a set of disjoint points and straight segments that defines the contour to be machined is given. Define the set, $S$, by offsetting the contour to the inside by the tool radius, $r$. From the definition of medial axis, it is clear that any circles inscribing the contour center on the medial axis of $S$. By using this, an algorithm to generate a trochoidal tool path is given as follows:

1. Compute the medial axis for $S, M A(S)$.

2. Choose the edges from $M A(S)$ on which trochoidal paths are assigned (denote it by $\left.M A_{C}(S)\right)$.

3. Let a point $p_{1}$ on $M A_{C}(S)$ be the start point. Find two segments in $S$ that are the closest to $p$. Draw a circle centered at $p_{1}$ that inscribes two segments.

4. Move the point $p_{i}(i=1, \cdots, N)$ on $M A_{C}(S)$ with the given pitch. At each $p_{i}$, draw an inscribed circle. The pitch is typically given such that the maximum radial depth of cut is kept constant. Repeat it until the end of $M A_{C}(S)$.

Figure 4 shows its illustrative example. To shorten the entire machining time, it is practically effective to replace an air-cut part in each circular path with a straight path. In Fig. 4, trochoidal paths are assigned only on a part of the medial axis. It is also possible to machine the entire pocket by trochoidal grooving only, by assigning trochoidal paths over all the edges on the medial axis, as has been shown by Elber et al. [16]. 


\section{Recognition of critical cutting regions by using me- dial axis}

\subsection{Recognition of critical cutting regions}

As has been discussed in Section 1, this paper parameterized the variation in cutting load by the engagement angle of a tool to the workpiece shown in Fig. 1. A part of the tool path that is subject to the engagement angle higher than the given threshold is called the critical cutting region in this paper. It should be emphasized that this paper focuses on the machining by a straight end mill, and thus, only the $2 \mathrm{D}$ interference between a tool and workpiece is considered. The engagement angle can be numerically computed [2, 14, 21]. As an example, consider contour-parallel tool paths shown in Fig. 5(a). The machining is conducted from the innermost path to the outermost path. The engagement angle is computed along the entire path by using the algorithm in [21] to extract regions subject to the engagement angle higher than 40 degrees, as shown in bold in Fig. 5(a).

Such a computation over the entire path requires high computational cost. The computational cost to extract critical cutting regions can be significantly reduced by using the medial axis. Figure 5(b) shows the medial axis of the pocket contour. It is clear that critical cutting regions are located only on and around the medial axis. It suggests that the computation of the engagement angle at the intersection of tool paths and the medial axis would be sufficient to extract critical cutting regions. 


\subsection{Insertion of trochoidal grooving}

By inserting trochoidal grooving to remove critical cutting regions in prior to contour-parallel paths, safer and faster contour-parallel machining can be conducted, eliminating a need for careful planning of machining conditions. Figure 5(c) shows an example of trochoidal paths of a constant radius assigned on a part of critical cutting regions. By using the algorithm presented in Section 2, a trochoidal path of variable radius to remove the region enclosed by one loop of contour-parallel paths can be generated as shown in Fig. 5(d), which can eliminate all contour-parallel paths inside this region.

Figure 6 illustrates a strategy to machine a slot. When the ratio of the finished workpiece radius, $R$, to the tool radius, $r$, is larger than the given threshold (in this example, $\frac{R}{r} \geq 2.0 \sim$ 3.0), a slot is finished by using the original contour-parallel path. In a critical cutting region

where $\frac{R}{r}$ is smaller than this threshold, the slot must be machined by trochoidal grooving. When $\frac{R}{r}$ is close to one, it often becomes difficult to safely machine even by trochoidal grooving. The reduction of axial depth of cut must be considered in such a case [8].

\section{Experimental case study \#1}

\subsection{Overview}

The effectiveness of the present machining strategy is experimentally demonstrated by two case studies to machine a mold of hardened steel. Figure 7 shows the geometry of a box mold to be machined in the first case study. The following two machining strategies are tested:

In Machining Strategy \#1, roughing and intermediate-roughing are conducted by using 
a straight end mill. Contour-parallel paths are used with applying the present strategy to remove critical cutting regions in priori by trochoidal grooving.

In Machining Strategy \#2, roughing and intermediate-roughing are conducted by using a ball end mill. Contour-parallel paths are generated by an expert machine operator using a commercial CAM software (TOOLS by Graphic Products, Inc.). Machining Strategy \#2 is considered to be a conventional strategy typically employed in industrial mold machining.

Since finishing operations by using a ball end mill are common in both strategies, we only compare roughing and intermediate-roughing operations. Both strategies are tested by using the same commercial vertical machining center. The workpiece, a rectangular block of the size $150 \mathrm{~mm} \times 150 \mathrm{~mm} \times 60 \mathrm{~mm}$, is pre-heated hardened die steel, JIS SKD61 of the hardness HRC53. In both strategies, oil air (pressure: $0.5 \mathrm{MPa}$ ) is used as cutting coolant. More details of both strategies will be presented in the following subsections.

\subsection{Machining Strategy \#1: Roughing by a straight end mill with trochoidal grooving}

Table 1 summarizes the machining procedure in Machining Strategy \#1. Except for helical boring by a ball end mill (Steps 1 and 5), a straight end mill is used. Machining conditions in each step are shown in Table 2. The cavity depicted in Fig. 7 is divided into four layers; first three layers are machined by Steps 1 to 4 with the axial depth of cut $10 \mathrm{~mm}$, and the last layer is machined by Steps 5 to 8 with the axial depth of cut $5 \mathrm{~mm}$. Step 9 represents a intermediate-roughing process by a straight end mill. Steps 4, 8, and 9 ("Side wall") represent contour-parallel cutting.

As an example, Fig. 8 shows tool paths in the first and fourth layers. Figure 9 shows 
critical cutting regions in the fourth layer, where the engagement angle becomes larger than 40 deg. Trochoidal paths are inserted only on a part of the medial axis at each layer. Several strategies, including the one where trochoidal paths are inserted over the entire medial axis, and the one where trochoidal paths are inserted only on the innermost path, are compared in their total machining time. Since more insertion of trochoidal grooving often lengthens the machining time due to the increase of air cut, we selected strategies shown in Fig. 8 in this experiment.

It is to be noted that the feedrate profile in contour-parallel cutting is scheduled such that the material removal rate is regulated constant. The feedrates shown in Steps 4,8 and 9 in Table 2 represent the value at a straight path. The feedrate profile in trochoidal grooving is also scheduled in an analogous manner as presented by Otkur and Lazoglu [14].

\subsection{Machining Strategy \#2: Conventional roughing by a ball end mill with contour-parallel paths}

In Machining strategy \#2, roughing and intermediate roughing processes are conducted by using a ball end mill of the radius $5 \mathrm{~mm}$. Table 3 shows machining conditions in Machining strategy \#2. The entire depth is divided into total 54 layers with the axial depth of cut 0.6mm. Contour-parallel paths are used in all layers. Since contour-parallel paths under the condition in Table 3 for hardened steel may cause a severe tool damage at corners, the following modifications were made on original contour-parallel paths: 1) an additional circular loop is inserted at a sharp corner [9] and 2) a feedrate profile is scheduled such that the material removal rate is regulated constant (same as in Machining Strategy \#2). Such modifications are made automatically by CAM software TOOLS. 


\subsection{Machining results}

Table 4 compares the total machining time and cutting distance in both cases. Machining strategy \#1 shortened the total machining time by 9 minutes $(21 \%)$. The total material removal rate under Strategy \#1 with a straight end mill was $6.53 \mathrm{cc} / \mathrm{min}$, larger than 5.21 cc/min under Strategy \#2 with a ball end mill. Figure 10 compares the tool wear in both cases when all the machining processes are finished. In both cases, only small normal wear $\left(V_{b}=0.04 \mathrm{~mm}\right.$ in Strategy \#1, and $V_{b}=0.1 \mathrm{~mm}$ in Strategy \#2) is observed. It indicates that both strategies performed safe machining with no excessive tool wear.

\section{Experimental case study \#2}

In the second case study, a cavity mold of an iron shown in Fig. 11 is machined. The same machining center and the same workpiece are used.

\subsection{Machining Strategy \#1: Roughing by a straight end mill with trochoidal grooving}

Similarly as in the first case study, Strategy \#1 uses a straight end mill of the diameter of $10 \mathrm{~mm}$ in all processes except for helical boring. Table 5 shows machining procedure and machining conditions in Strategy \#1. Since the bottom surface of the cavity is not horizontal, the axial depth of cut is set to $5 \mathrm{~mm}$, smaller than that in the first case study, not to leave large leftover to the intermediate-roughing process. Total five layers are to be machined.

Figure 12 shows tool paths in the first layer. Trochoidal paths are inserted in critical cutting regions. The upper-left slot is machined only by trochoid cycles of variable radius. 
Notice that "Region A" in Fig. 12 is too narrow to insert trochoidal grooving (see Section 3.2). Full-immersion slotting with a smaller axial depth of cut $(0.5 \mathrm{~mm})$ are repeatedly conducted to machine this region.

\subsection{Machining Strategy \#2: Conventional roughing by a ball end mill with contour-parallel paths}

Machining Strategy \#2 conducts roughing by using a ball end mill of the radius $5 \mathrm{~mm}$. The axial depth of cut is set to $0.6 \mathrm{~mm}$. Table 6 shows machining conditions. Contour-parallel paths are used in all the layers. Similarly as in the first case study, feedrate scheduling and the insertion of corner loops are done by CAM software TOOLS.

\subsection{Machining results and discussion}

Table 7 compares the machining time in both cases. Machining strategy \#1 shortened the total machining time by 4' 36 ".

The cavity in the first case study has a flat bottom and almost vertical side walls. In such a case, the machining by a straight end mill exhibits larger improvement in the machining productivity, since it allows larger axial depth of cut. In the second case study, the cavity has a slightly slanted bottom surface, and the pocket depth is relatively small $(25 \mathrm{~mm})$ with respect to the tool diameter. This is a major reason why Strategy \#1 showed only a slight reduction of machining time.

It should be noted that the conventional strategy (Strategy \#2) requires an expert operator to carefully design machining conditions in order to obtain the machining results shown in two case studies. Even with feedrate scheduling, it is difficult to choose proper feedarte 
and spindle speed to avoid tool damage at corners, while maximizing the machining efficiency. The removal of critical cutting regions by trochoidal grooving significantly facilitates process planning.

\section{Conclusion}

Roughing by a straight end mill potentially enhances the productivity of die and mold machining significantly. A straight end mill allows larger axial depth of cut than a ball end mill, which significantly reduces the number of layers in the z-direction in $2-1 / 2$ dimensional machining. In two-dimensional machining by a straight end mill, however, the tool is typically subject to higher tool load. Therefore, very careful design of tool paths and machining conditions is crucial. The removal of critical cutting regions, in prior to contour-parallel cutting, is effective to perform safe machining. Two case studies showed the effectiveness of the proposed tool path planning scheme to enhance the overall productivity without sacrificing the tool life in high speed machining by using a straight end mill. 


\section{References}

[1] Kline, W. A., Devor, R. E., and Lindberg, J., 1982, "Prediction of Cutting Forces in End Milling with Application to Cornering Cuts," Int. J. of Machine Tools Design and Research, 22, pp. 7-22

[2] Choy, H. S., Chan, K. W., 2003, "Modeling Cutter Swept Angle at Cornering Cut," Int. J. of $C A D / C A M, 3(1), 1-12$.

[3] Tlusty, J., Smith, S., Zamudio, C., 1990, "New NC Routines for Quality in Milling," Annals of the CIRP, 39(1), 517-521.

[4] Liang, S.Y. Hecker, R. L., Landers, R. G., "Machining process monitoring and control: The state-of-the-art," Trans. of ASME, J. of Manufacturing Science and Engineering, 126-2, pp. 297-310, 2004.

[5] Ulsoy, A. G., Koren, Y. "Control of Machining Processes,", ASME J. of Dynamic Systems, Measurement, and Control, 115, pp. 301-308, 1993.

[6] Matsubara, A., Ibaraki, S., 2009, "Monitoring and Control of Cutting Forces in Machining Processes: A Review," Int'l J. of Automation Technology, 3(4), 445-456.

[7] Otsuka, H., Kakino, Y., Matsubara, A., Nakagawa, H., Hirogaki, T., 2001, "A Study on Endmilling of Hardened Steel (2nd Report) - Control for Constant Cutting Forces in Corner Profile Endmilling Including Connection Areas of Tool Paths -," J. of the Japan Society for Precision Engineering, 67 (8), 1294-1298 (in Japanese). 
[8] Yamaji, I, 2003, “An Intelligent Die and Mold Machining System," Ph.D. dissertation, Kyoto University (in Japanese).

[9] Iwabe, H., Fuji, Y., Saito, K. Kishinami, T., 1989, "Study on Corner Cut by End Mill Analysis of Cutting Mechanism and New Cutting Method at Inside Corner," J. of Japan Society of Precision Engineering, 99(5), 841-846.

[10] Tsai, M. D., Takata, S, Inui, M., Kimura, F. and Sata T., 1991, "Operation Planning Based on Cutting Process Models," Annals of the CIRP, 40(1), 95-98.

[11] Choy, H. S. Chan, K. W., 2003, "A Corner-looping Based Tool Path for Pocket Milling," Computer-Aided Design, 35, 155-166.

[12] Rauch, M., Duc, E., Hascoet, J. Y., 2009, "Improving trochoidal tool paths generation and implementation using process constraints modelling", Int'l J. of Machine Tools and Manufacture, 49 (5), 375-383.

[13] Law, K. M.Y. Geddam A., Ostafiev, V. A., 1999, "A process-design approach to error compensation in the end milling of pockets," J. of Materials Processing Technology, 89-90, 238-244.

[14] Otkur, M., Lazoglu, I., 2007, "Trochoidal Milling," Int'l J. of Machine Tools and Manufacture, 47 (9), 1324-1332.

[15] Ibaraki, S., Yamaji, I., Matsubara, A., Kakino, Y., Inoue, D., Nishida, S., 2003, "Tool path planning trochoid cycles for hardened steel in die and mold manufacturing (1st report) - tool path generation for trochoid cycles based on Voronoi diagram -," Proc. of the Int'l Conf. on Agile Manufacturing, 435-442. 
[16] Elber, G., Cohen, E., Drake, S.. 2004, "MATHSM: Medial axis transform toward high speed machining of pockets," Computer Aided Design, 37(2), 241-250.

[17] Held, M, 1991, On the computational geometry of pocket machining, Lecture Notes in Computer Science vol.500, Springer.

[18] Dragomatz, D., Mann, S., 1997, "Survey - A Classified Bibliography of Literature on NC Milling Path Generation," Computer Aided Design, 29(3),239-247.

[19] Persson, H., 1978, "NC machining of arbitrarily shaped pockets," Computer Aided Design, 10(3), 169-174.

[20] Held, M, 2001, "VRONI: An Engineering Approach to the Reliable and Efficient Computation of Voronoi Diagrams of Points and Line Segments," Computational Geometry: Theory and Application, 18(2) 95-123.

[21] Uddin, M. S., Ibaraki, S., Matsubara, A., Nishida, S., Kakino, Y., 2007, "A Tool Path Modification Approach to Cutting Engagement Regulation for the Improvement of Machining Accuracy in 2D Milling with a Straight End Mill," Trans. of the ASME, J. of Manufacturing Science and Engineering, 129 (6), 1069-1079. 


\section{List of Tables}

$1 \quad$ Machining procedure (Machining strategy \#1: Proposed) . . . . . . . . 18

2 Machining conditions (Machining strategy \#1) . . . . . . . . . 19

$3 \quad$ Machining conditions (Machining strategy \#2) . . . . . . . . . . . 20

4 Comparison in machining time and cutting length (Case study \#1) . . . . 21

$5 \quad$ Machining conditions (Machining strategy \#1) . . . . . . . . . . 22

6 Machining conditions (Machining strategy \#2) . . . . . . . . . . 23

$7 \quad$ Comparison in machining time and cutting length (Case study \#2) . . . . 24

\section{List of Figures}

1 Engagement angle. . . . . . . . . . . . . . . . 25

2 Trochoidal grooving. . . . . . . . . . . . . . . 26

3 An example of the Voronoi diagram and the medial axis [17]. . . . . . . . . 28

4 An example of trochoidal tool path computed by using the medial axis . . . . . . 29

$5 \quad$ Recognition of critical cutting regions and insertion of trochoidal paths. . . . . . 33

6 Grooving strategies . . . . . . . . . . . . . . . . . 34

$7 \quad$ Mold geometry $($ Case Study \#1) . . . . . . . . . . . . . . . . 35

8 Tool paths with trochoidal grooving (Machining Strategy \#1) . . . . . . . 37

9 Critical cutting regions on contour parallel paths in the fourth layer . . . . . . 38

10 Comparison in tool wear. . . . . . . . . . . . . . . . 40

11 Mold geometry (Case Study \#2) . . . . . . . . . . . . . . . . . 41

12 Tool paths with trochoidal grooving (Strategy \#1) . . . . . . . . . . 42 
Table 1: Machining procedure (Machining strategy \#1: Proposed)

\begin{tabular}{|c|l|l|}
\hline Step & Geometry & Machining process (end mill) \\
\hline 1 & Hole & Helical boring (ball) \\
2 & Hole expansion & Spiral hole expansion (straight) \\
3 & Slot & $\begin{array}{l}\text { Trochoidal grooving (straight) } \\
\text { slot width: } 20 \mathrm{~mm} \text {, slot length: } 60 \mathrm{~mm}\end{array}$ \\
4 & Side wall & Contour-parallel cutting (straight) \\
5 & Hole & Helical boring (ball) \\
6 & Hole expansion & Spiral hole expansion (straight) \\
7 & Slot & Trochoidal grooving (straight) \\
8 & Side wall & Contour-parallel cutting (straight) \\
9 & Side wall & Intermediate-rough side cutting (straight) \\
\hline
\end{tabular}


Table 2: Machining conditions (Machining strategy \#1)

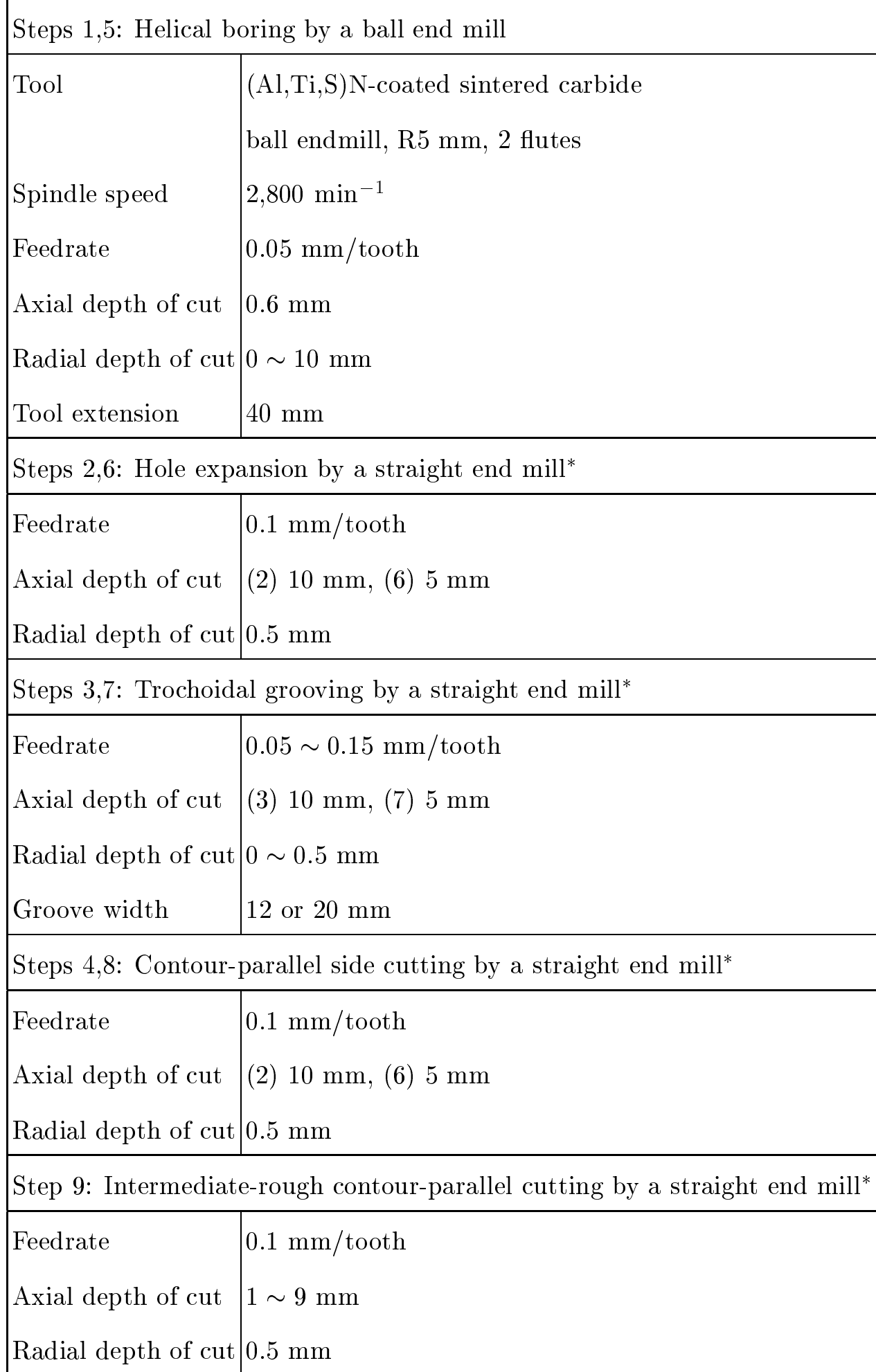

* Tool: (Al, Ti, S)N-coated sintered carbide straight endmill, $\phi 10 \mathrm{~mm}, 6$ flutes, Tool extension: 40mm, Spindle speed: $4,800 \mathrm{~min}^{-1}$ 
Table 3: Machining conditions (Machining strategy \#2)

\begin{tabular}{|l|l|}
\hline \multicolumn{2}{|l|}{ All layers } \\
\hline Tool & $\begin{array}{l}\text { (Al, Ti, S)N-coated sintered } \\
\text { carbide ball endmill, R5 mm, } 2 \text { flutes }\end{array}$ \\
Spindle speed & $4,800 \mathrm{~min}^{-1}$ \\
Feedrate & $0.05 \mathrm{~mm} /$ tooth \\
Axial depth of cut & $0.6 \mathrm{~mm}$ \\
Radial depth of cut & $3.5 \mathrm{~mm}$ \\
Tool extension & $40 \mathrm{~mm}$ \\
\hline
\end{tabular}


Table 4: Comparison in machining time and cutting length (Case study \#1)

\begin{tabular}{|l|l|l|}
\hline & Machining strategy \#1 & Machining strategy \#2 \\
\hline Tool & $\phi 10 \mathrm{~mm}$ straight endmill & R5 mm ball endmill \\
\hline Machining & Helical boring: 3'30" & Contour-parallel \\
time & Hole expansion: 4'00” & rough cutting: \\
& Rough cutting: 23'18' & $42^{\prime} 47^{\prime \prime}$ \\
Total time & Interm. cutting: 3'03' & \\
Cutting length & $33^{\prime} 51^{\prime \prime}$ & $42^{\prime} 47^{\prime \prime}$ \\
$56.07 \mathrm{~m}$ & $153.9 \mathrm{~m}$ \\
\hline
\end{tabular}


Table 5: Machining conditions (Machining strategy \#1)

(1) Helical boring by a ball end mill

Same as in Table 2 .

(2) Hole expansion by a straight end mill

Same as in Table 2.

(3) Trochoidal grooving by a straight end mill

\begin{tabular}{l|l}
\hline Spindle speed & $2,400 \sim 9,600 \mathrm{~min}^{-1}$ \\
Feedrate & $0.05 \sim 0.08 \mathrm{~mm} /$ tooth \\
Axial depth of cut & $5.0 \mathrm{~mm}\left(0.5 \mathrm{~mm}^{*}\right)$ \\
Radial depth of cut & $0.5 \mathrm{~mm}$ \\
Groove width & $12 \sim 20 \mathrm{~mm}$ \\
\hline
\end{tabular}

(4) Contour-parallel roughing by a straight end mill

\begin{tabular}{l|l}
\hline Spindle speed & $9,600 \mathrm{~min}^{-1}$ \\
Feedrate & $0.08 \mathrm{~mm} /$ tooth \\
Axial depth of cut & $5.0 \mathrm{~mm}$ \\
Radial depth of cut & $0.5 \mathrm{~mm}$ \\
\hline
\end{tabular}

* Region A in Fig. 12 is machined by full-immersion slotting with smaller axial depth of cut. 
Table 6: Machining conditions (Machining strategy \#2)

\begin{tabular}{|l|l|}
\hline \multicolumn{2}{|l|}{ All layers } \\
\hline Spindle speed & $10,000 \mathrm{~min}^{-1}$ \\
Feedrate & $0.3 \mathrm{~mm} /$ tooth \\
Axial depth of cut & $0.6 \mathrm{~mm}$ \\
Radial depth of cut & $4.0 \mathrm{~mm}$ \\
\hline
\end{tabular}


Table 7: Comparison in machining time and cutting length (Case study \#2)

\begin{tabular}{|l|l|l|}
\hline & Machining strategy \#1 & Machining strategy \#2 \\
\hline Tool & $\phi 10$ mm straight endmill & R5 mm ball endmill \\
\hline Machining & Helical boring: 4'48” & Contour-parallel \\
time & Hole expansion: 2'06” & Roughing: \\
& Trochoidal+ & \\
& Contour-parallel 23'33' & $355^{\prime} 05^{\prime \prime}$ \\
Total time & $30^{\prime} 27^{\prime \prime}$ & \\
Cutting length & $54.3 \mathrm{~m}$ & $35^{\prime} 05^{\prime \prime}$ \\
\hline
\end{tabular}




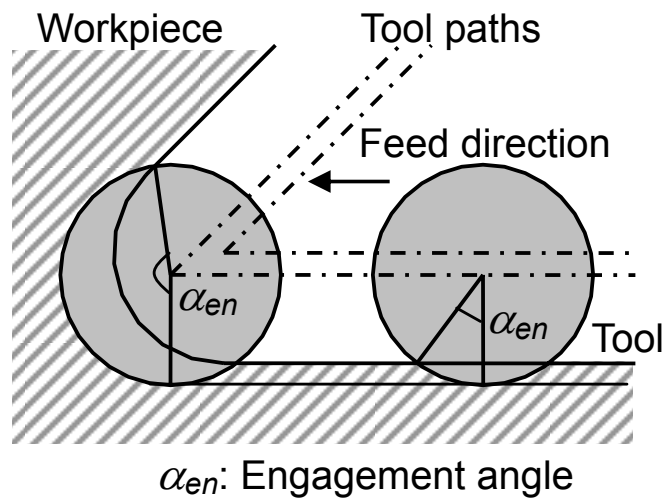

Figure 1: Engagement angle. 


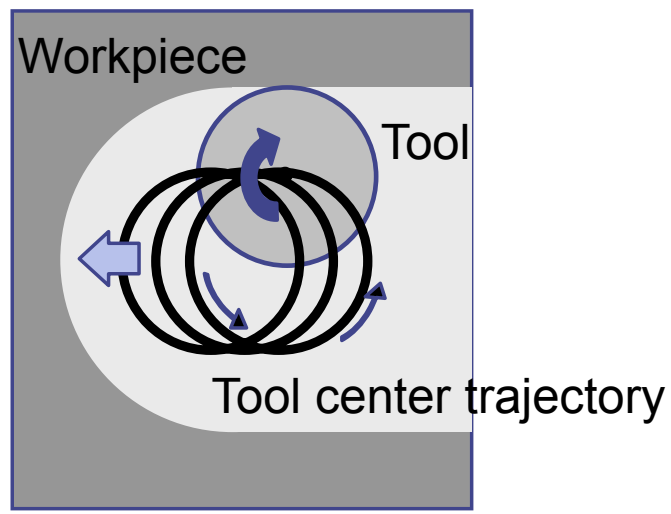

Figure 2: Trochoidal grooving. 


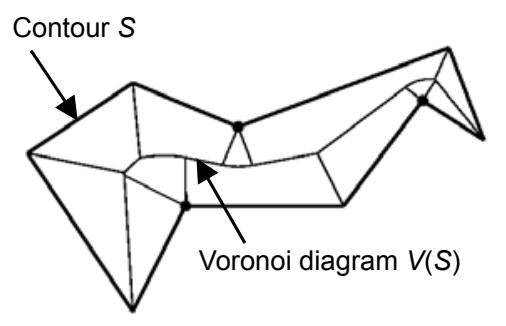

(a) Voronoi diagram. 


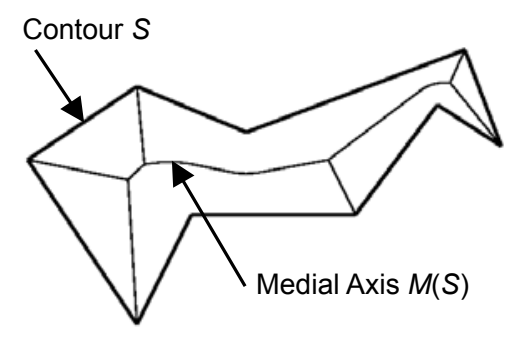

(b) Medial axis.

Figure 3: An example of the Voronoi diagram and the medial axis [17]. 


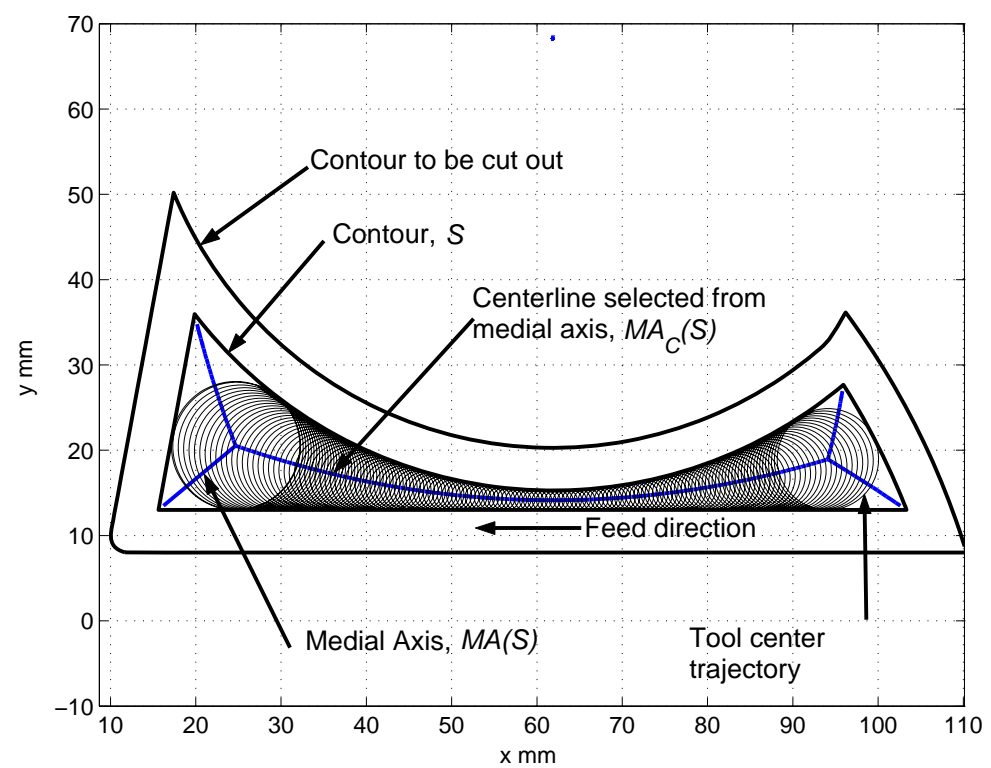

Figure 4: An example of trochoidal tool path computed by using the medial axis 


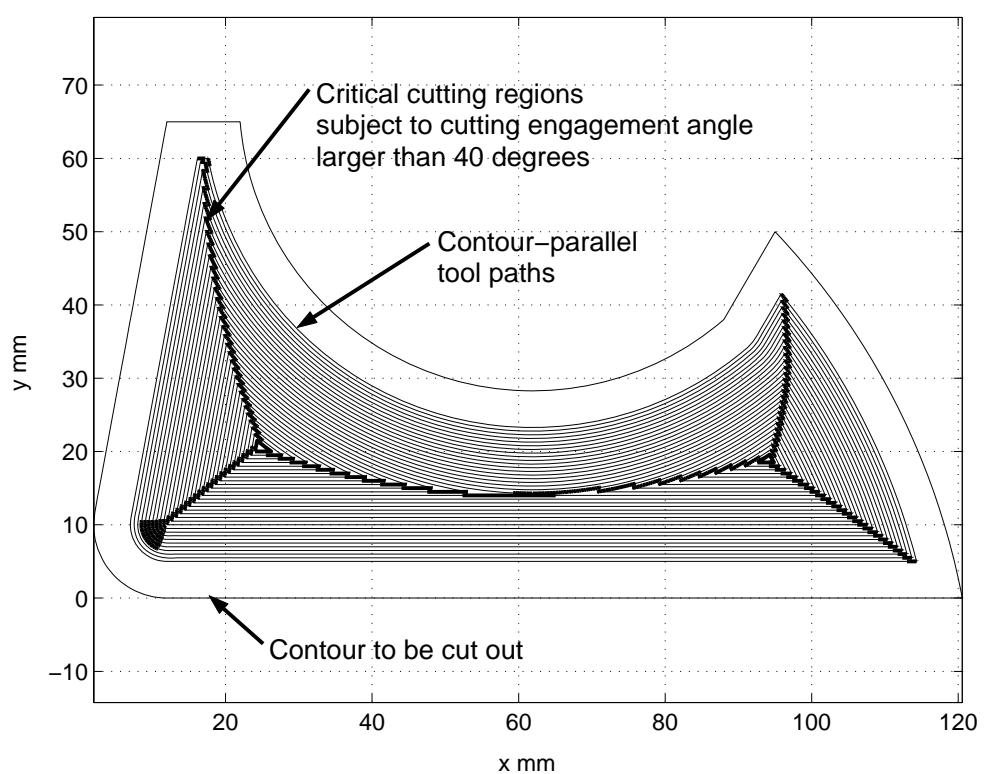

(a) Contour-parallel tool paths and critical cutting regions subject to the engagement angle higher than 40 degrees. 


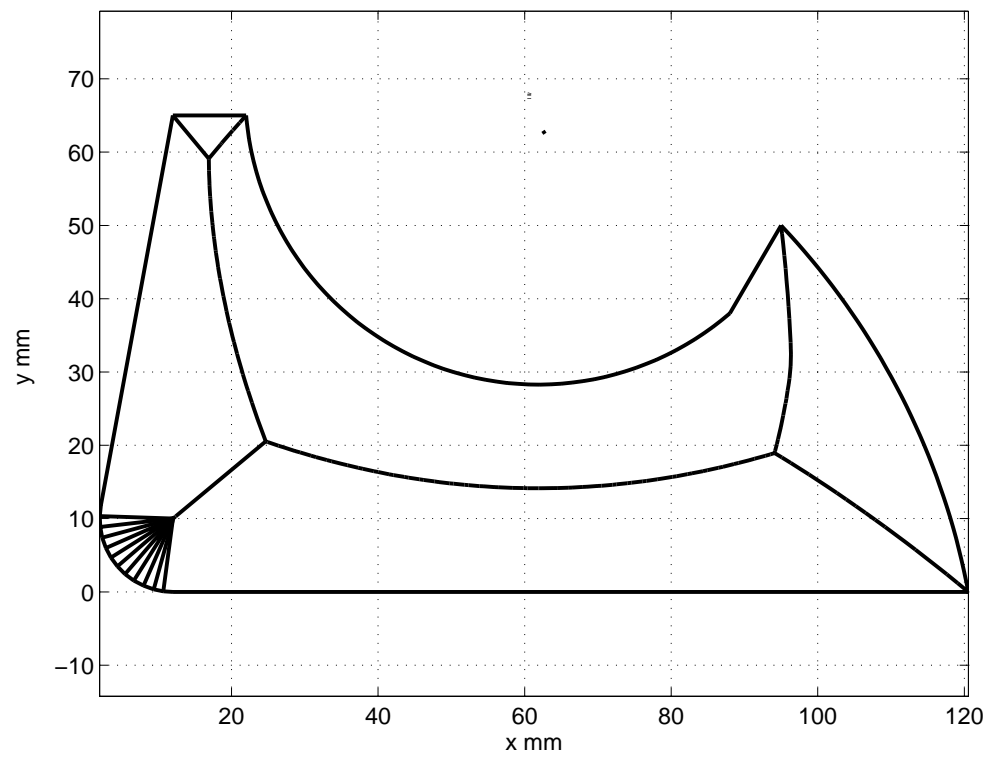

(b) Medial axis. 


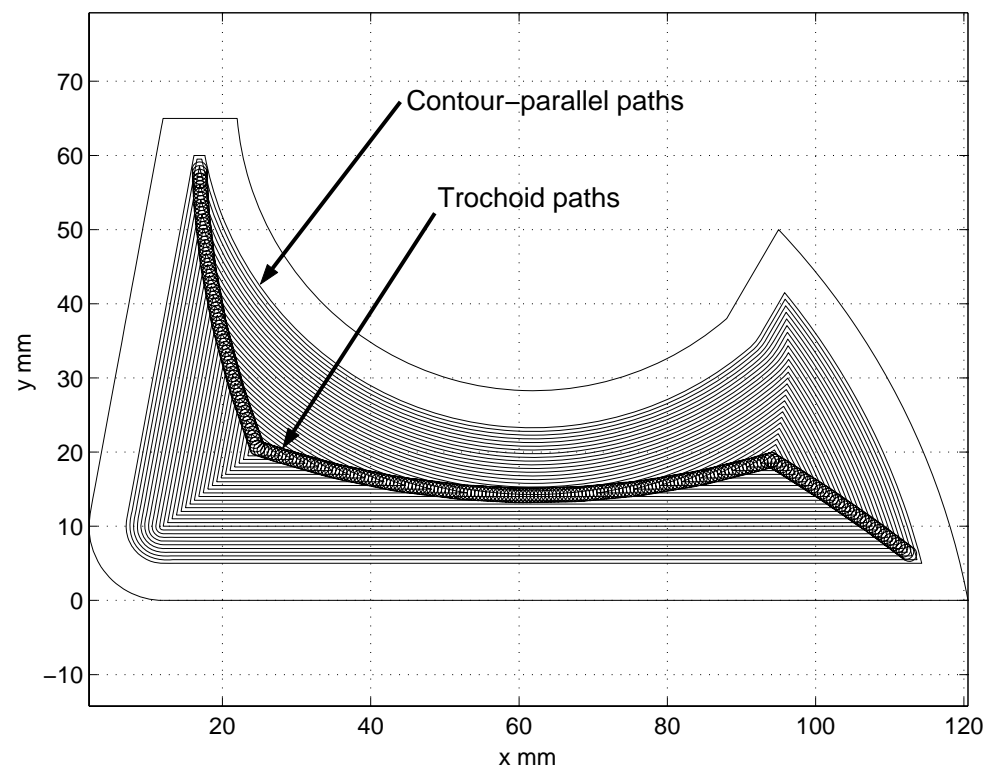

(c) Trochoidal paths of constant radius inserted over critical cutting regions. 


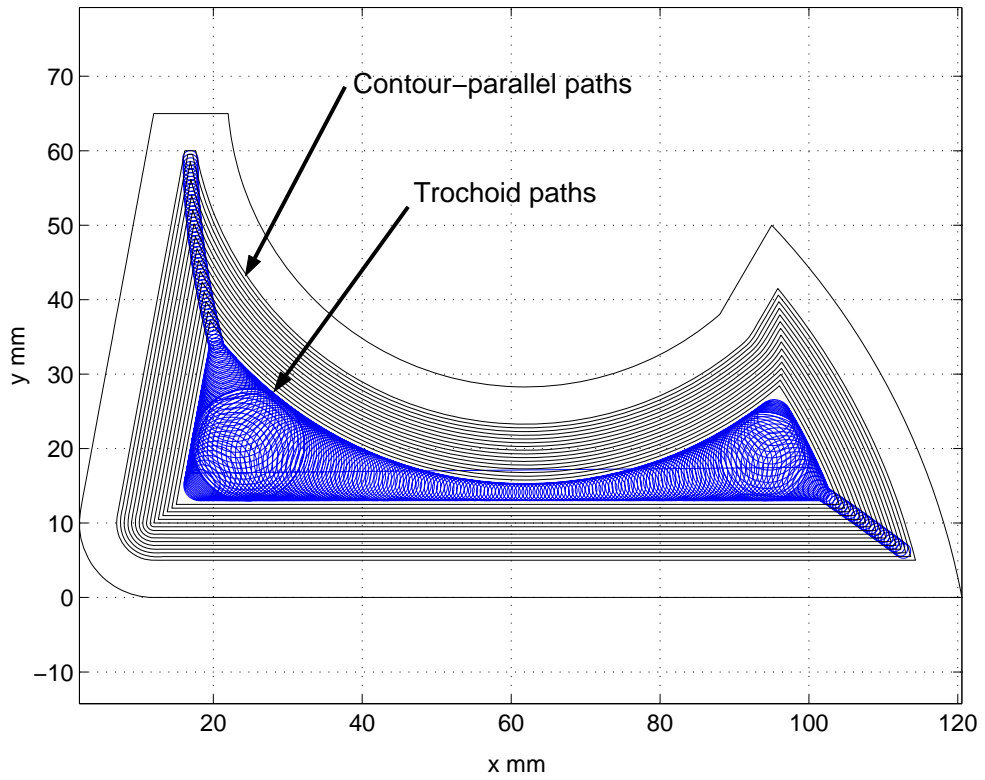

(d) Trochoidal paths of variable radius inserted over critical cutting regions.

Figure 5: Recognition of critical cutting regions and insertion of trochoidal paths. 


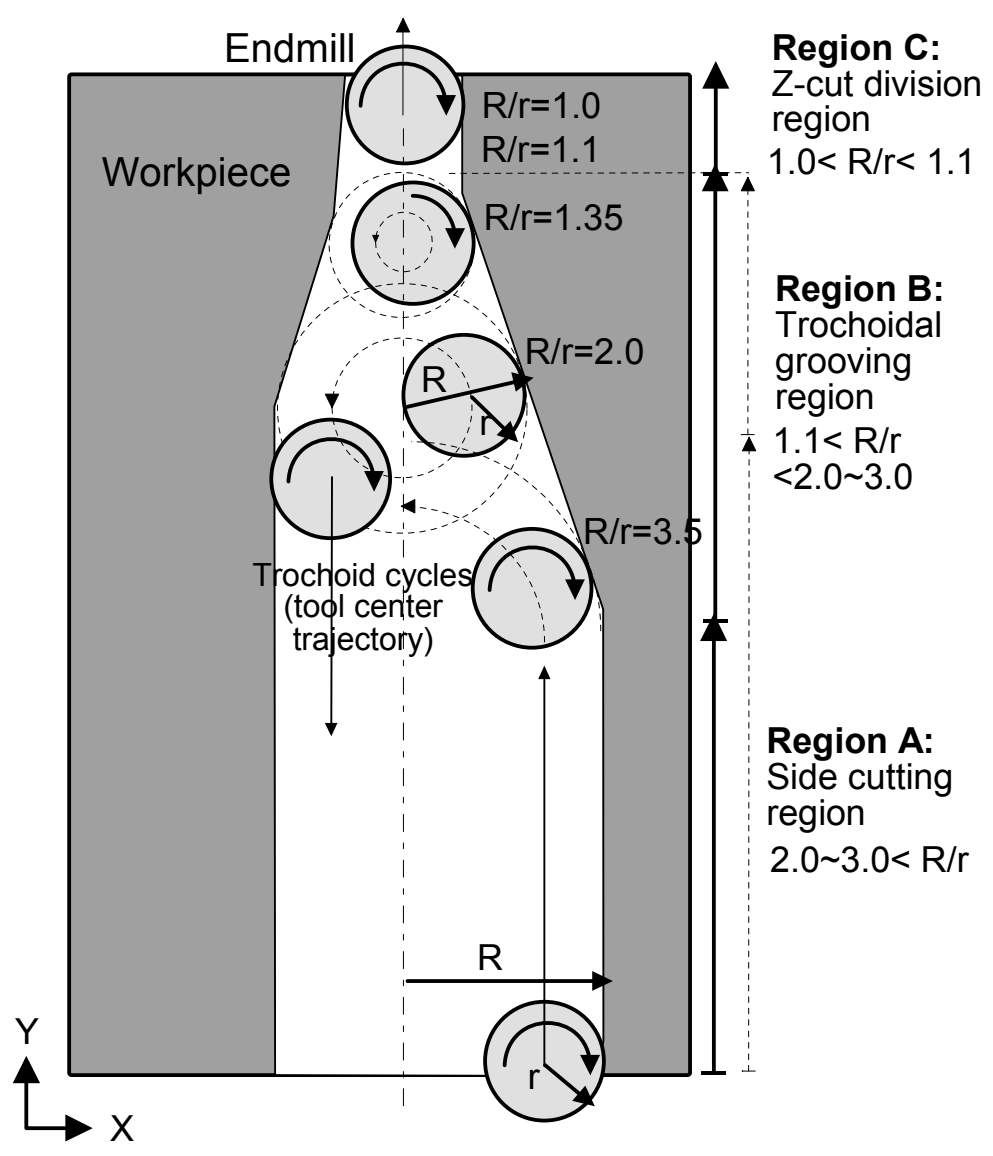

Figure 6: Grooving strategies 


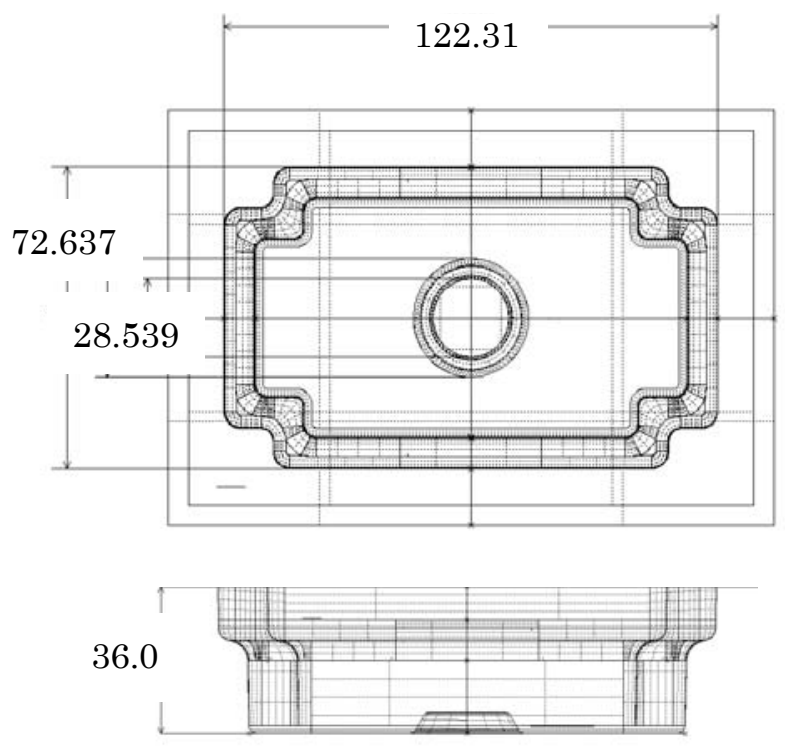

Figure 7: Mold geometry (Case Study \#1) 


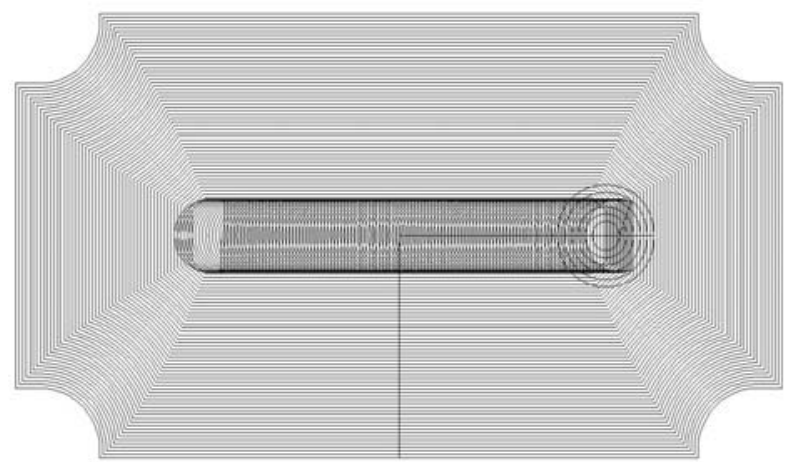

(a) First layer 


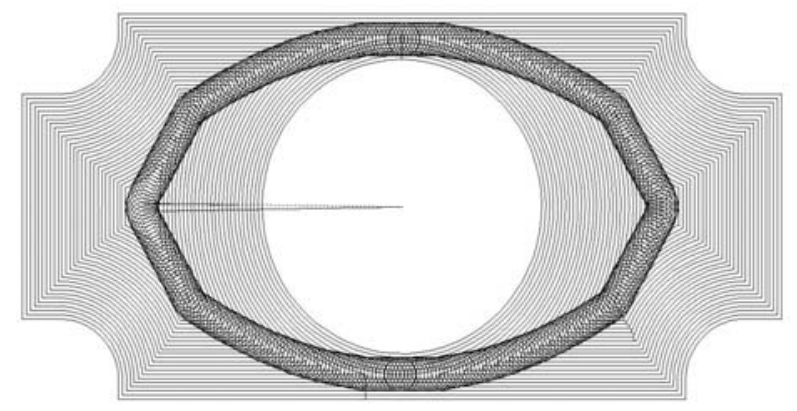

(b) Fourth layer

Figure 8: Tool paths with trochoidal grooving (Machining Strategy \#1) 


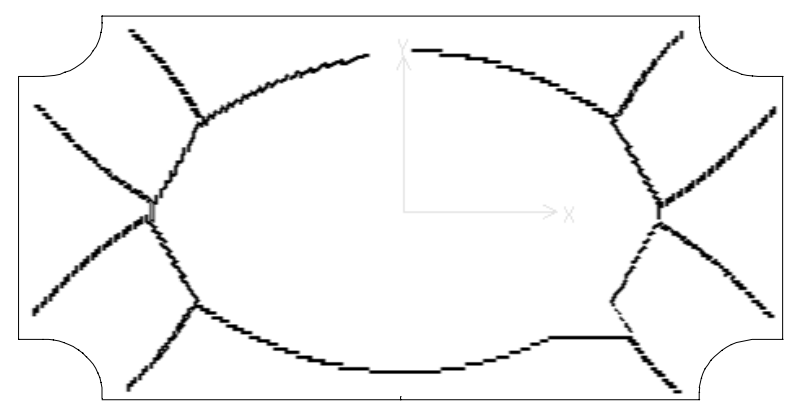

Figure 9: Critical cutting regions on contour parallel paths in the fourth layer 


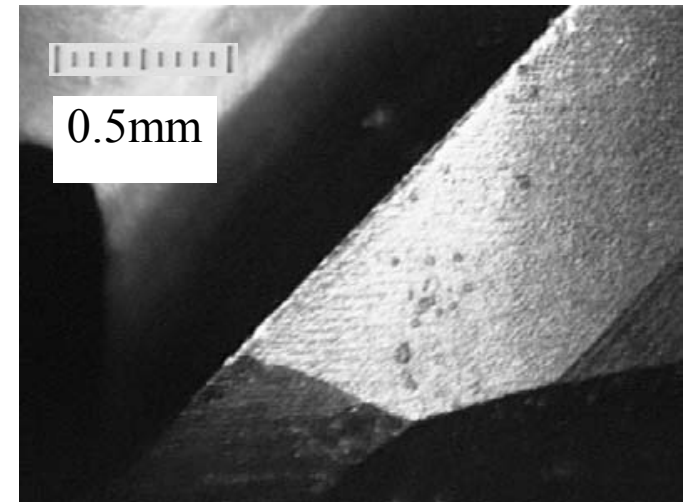

(a) Strategy \#1 (straight endmill, tool tip) 


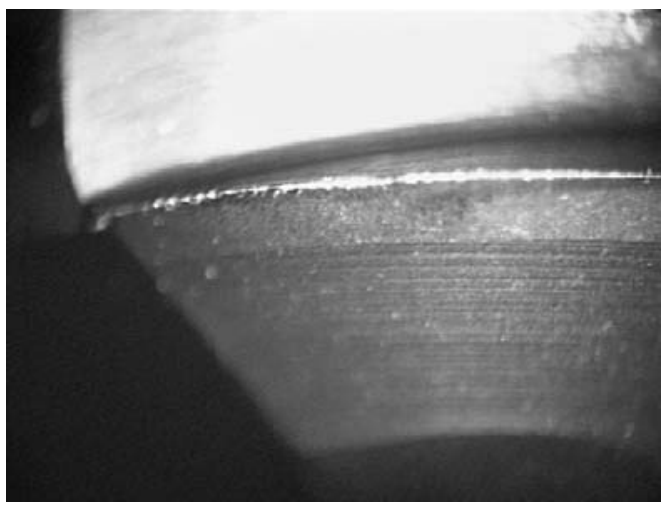

(b) Strategy \#2 (ball endmill)

Figure 10: Comparison in tool wear. 

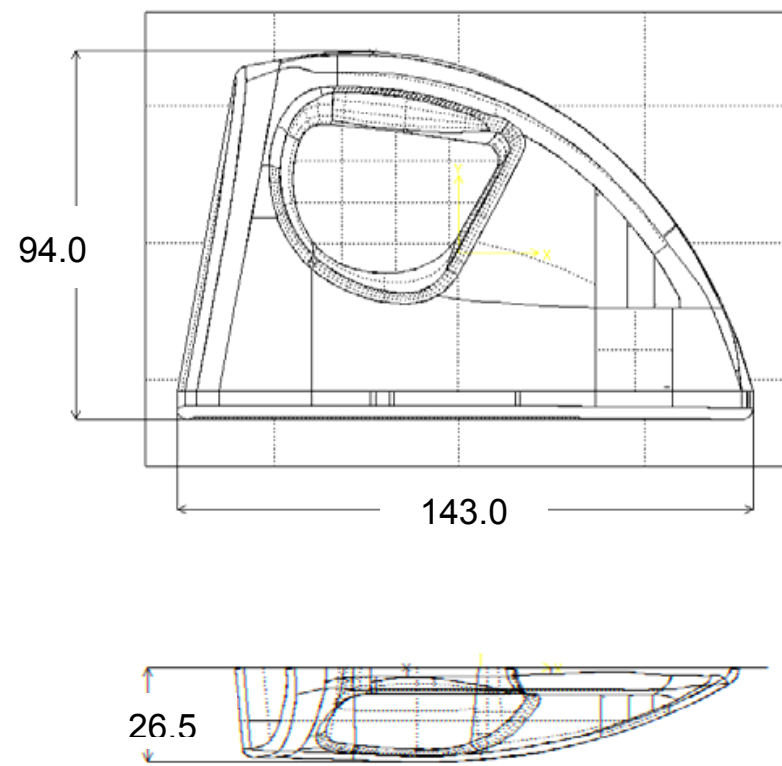

Figure 11: Mold geometry (Case Study \#2) 


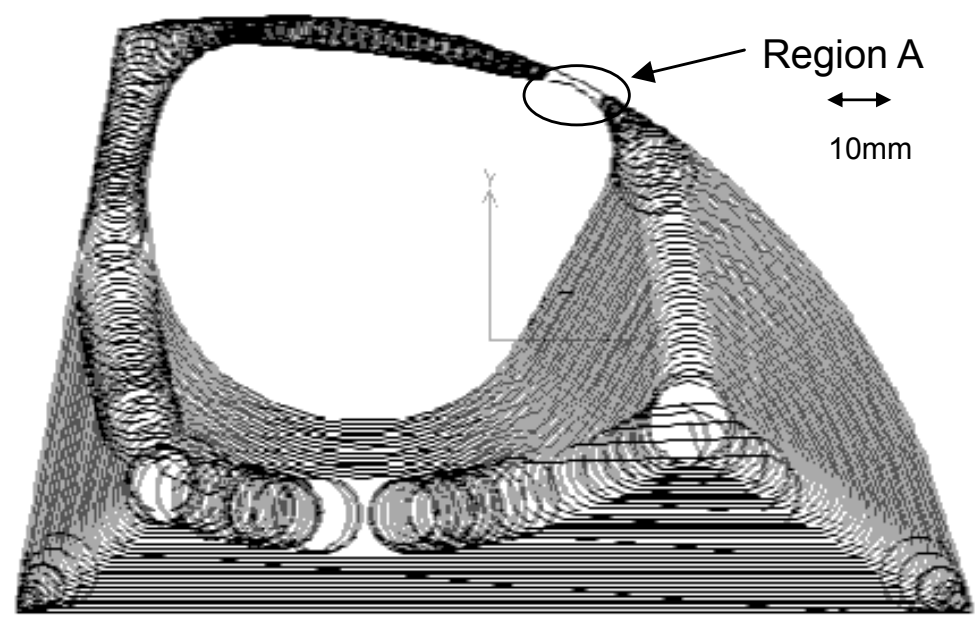

Figure 12: Tool paths with trochoidal grooving (Strategy \#1). 